\title{
Percutaneous nephrolithotomy in patients with a solitary kidney
}

\author{
Tufan Süelözgen, Salih Budak, Orcun Celik, Okan Yalbuzdag, Oguz Mertoglu, Selcuk Isoglu, \\ Mehmet Yoldas, Yusuf Ozlem Ilbey
}

Tepecik Training and Research Hospital, Urology Clinic, Izmir, Turkey.

\begin{abstract}
Summary Material and method: The results of percutaneous nephrolithotomy applied to 716 patients in our clinic between January 2008 and January 2014 were retrospectively evaluated.

Age, gender, urinary calculi size $\left(\mathrm{mm}^{2}\right)$, urinary calculi localization, ESWL history, operation duration (min), fluoroscopy duration (sec), access type, reason of solitary kidney, hemoglobin drawdown (g/dl) and operation success of the patients with a solitary kidney were recorded. The patients having no preoperative and postoperative non contrast abdominal tomography were excluded from the study.

Results: Fifteen of nineteen patients (79\%) were men and 4 of them (21\%) were women. The average age of the patients was $42.52 \pm 16.72$ (14-72). Ten patients had anatomical solitary kidney and nine patients had physiological solitary kidney. In fact counter kidney was non functional in 9 patients (47\%) whereas there was agenesis in $2(11 \%)$ and outcome of nephrectomy in 8 (42\%) patients. In our study, presence of residual stone less than $4 \mathrm{~mm}$ at $1^{\text {st }}$ month postoperative non contrast abdominal tomography was accepted as a successful result and accordingly our success rate was detected as $84 \%$.

Mean urinary calculi size was $405 \pm 252.9 \mathrm{~mm}^{2}$; urinary calculi localization was pelvic, lower pole, upper-middle pole, middle-lower pole and staghorn in $11(58 \%)$, $4(21 \%), 1(5 \%), 1(5 \%)$ and 1 (5\%) patients, respectively; previous ESWL history was 16\%; operation duration was $55.47- \pm 28.1 \mathrm{~min}$ and fluoroscopy duration $131.10 \pm 87.6$ sec; access type was subcostal in $79 \%$, supracostal in $10.5 \%$ and multiple in $10.5 \%$; hemoglobin drawdown was $1.75 \pm 0.97 \mathrm{mg} / \mathrm{dl}$.

Conclusions: PNL can be effectively and safely administered for the treatment of solitary kidney. In the treatment of large urinary calculi in patients with a solitary kidney, PNL has some advantages such as short surgery duration, less complication, acceptable hemoglobin drawdown and high success rates. According to our study, PNL operation in patients with a solitary kidney is a good option for carefully and poisedly selected cases.
\end{abstract}

KEY WORDS: Percutaneous nephrolithotomy; Solitary kidney; Urinary calculi.

Submitted 21 July 2014; Accepted 18 August 2014

\section{INTRODUCTION}

Urinary tract calculus disease continues to be a major health problem in our country. In a study conducted in 2011, calculus prevalence was determined as $11.1 \%$ and it was emphasized that our country has been among endemic countries (1). It was stated that $2.2 \%$ of general population was treated due to urinary tract calculus disease and $16 \%$ of them had more than one procedure (2). Percutaneous nephrolithotomy (PNL) in the trratment of urinary calculi was firstly described by Fernström and Johansson in 1976 (3). Since it was first developed, PNL procedure has been refined by means of improvements of optical system, endo-camera, lithotripsy energy systems, design of the nephroscope and advances in its accessories. As a result of all these improvements, need for open surgery in current urology practice is decreased to $0.7-4 \%$ and PNL has replaced it as first choice in the treatment of large urinary calculi (4).

In this study, we retrospectively examined the patients with a solitary kidney who underwent PNL operation and we evaluated the results of the treatment.

\section{MATERIAL AND METHODS}

The results of percutaneous nephrolithotomy applied to 716 patients in our clinic between January 2008 and January 2014 were retrospectively evaluated. Nineteen patients with a solitary kidney were included in the study. In our clinic, preoperative complete blood count, biochemical tests, including urea and creatinine levels, and urine culture are carried out for all patients who are planned to be treated with PNL. The patients were informed about operation and informed consent was obtained. One hour before the operation, antibiotic prophylaxis was carried out via parenteral administration of second generation cephalosporin. Age, gender, urinary calculi size $\left(\mathrm{mm}^{2}\right)$, urinary calculi localization, extracorporeal shock wave lithotripsy (ESWL) history, operation duration ( $\mathrm{min}$ ), fluoroscopy duration (sec), access type, reason of solitary kidney, hemoglobin drawdown (mg/dl) and operation success of the patients with a solitary kidney were recorded. The patients having no preoperative and postoperative non contrast abdominal tomography were excluded from the study. 
In lithotomy position, a $5 \mathrm{~F}$ open-end catheter was inserted in the ureter via a $22 \mathrm{~F}$ cystoscope under general anesthesia and set to a Foley catheter by a silk suture. Then, prone position was given to the patient. Collecting system was visualized with fluoroscopy by injection of opaque contrast through the ureteral catheter.

Percutaneous needle access to the urinary tract was obtained by bi-planar planning of the access site. Tract was dilated with Amplatz dilators over guide wire and a 30 F Amplatz sheath was placed. Kidney collecting system was entered by a $22 \mathrm{~F}$ rigid nephroscope. Ultrasonic lithotripter was preferred for litotripsy and pneumatic lithotripter was used when necessary.

After evaluation of the last fluoroscopy images, a $14 \mathrm{~F}$ Malecot nephrostomy catheter was placed and the operation was completed. All patients were followed up with non contrast abdominal tomography one month after operation.

\section{RESULTS}

Fifteen of nineteen patients (79\%) were men and 4 of them (21\%) were women.

The average age of the patients was $42.52 \pm 16.72$ (1472). Ten patients had anatomical solitary kidney and 9 patients had physiological solitary kidney. In fact counter kidney was non functional in 9 patients (47\%) whereas there was agenesia in $2(11 \%)$ and outcome of nephrectomy in 8 (42\%) patients. There was no previous history of surgery of the solitary kidney in all the patients. ESWL was administered to three patients (16\%) but it was not successful.

Stones location was pelvic, lower pole, upper-middle pole, middle-lower pole and staghorn in 11 (58\%), 4 (21\%), $1(5 \%), 1(5 \%)$ and $1(5 \%)$ patients, respectively. Average stone size was $405 \pm 252.9 \mathrm{~mm}^{2}$ (100-1050). Subcostal lower calyx access was performed in 15 of 19 patients (79\%). Intercostal upper pole access was carried out in two patients (10.5\%) and multiple intercostal and subcostal accesses were required in two patients (10.5\%). Average operation duration was $55.47 \pm 28.1$ (21-139) minutes and average duration of fluoroscopy use was $131.10 \pm 87.6(35-351)$ seconds. Average decrease in hemoglobin level of patients was $1.75 \pm 0.97$ (03-4.4) g/dl in postoperative period, but blood transfusion was not required.

Three patients developed fever in postoperative period. No further complication developed. At follow-up of the patients, residual stones were detected in 4 patients (21\%) at non contrast abdominal tomography one month after operation.

Three of these (75\%) were larger than $4 \mathrm{~mm}$ and $1 \%$ (25\%) was less than $4 \mathrm{~mm}$.

Presence of residual stones less than $4 \mathrm{~mm}$ was considered as a successful result and therefore our success rate was estimated as $84 \%$.

\section{Table 1.}

Characteristics and clinical outcome of percutaneous nephrolithotomy in patients with a solitary kidney.

\begin{tabular}{|c|c|c|c|c|c|c|c|c|c|c|c|}
\hline No & Age & Gender & $\begin{array}{c}\text { Stone-size } \\
\left(\mathrm{mm}^{2}\right)\end{array}$ & $\begin{array}{c}\text { Stone } \\
\text { location }\end{array}$ & $\begin{array}{l}\text { ESWL } \\
\text { history }\end{array}$ & $\begin{array}{l}\text { Operation } \\
\text { time(min) }\end{array}$ & $\begin{array}{c}\text { Skope } \\
\text { time(sec) }\end{array}$ & $\begin{array}{l}\text { Approach } \\
\text { time }\end{array}$ & Why soliter & $\begin{array}{l}\text { Decrease of } \\
\text { hemoglobine }\end{array}$ & $\begin{array}{l}\text { Operation } \\
\text { succes }\end{array}$ \\
\hline 1 & 43 & $M$ & 625 & Pelvis & No & 67 & 94 & Subcostal & Nonfunctional & 1.4 & $\begin{array}{c}\text { Residue } \\
\text { (more than } 4 \mathrm{~mm} \text { ) }\end{array}$ \\
\hline 2 & 53 & $M$ & 277 & Upper middle Pole & No & 90 & 222 & Multiple access & Nonfunctional & 3.7 & Stonefree \\
\hline 3 & 20 & $M$ & 625 & Pelvis & No & 55 & 141 & Subcostal & Nonfunctional & 0.9 & Stonefree \\
\hline 4 & 66 & M & 280 & Pelvis & No & 28 & 82 & Subcostal & Nonfunctional & 0.5 & Stonefree \\
\hline 5 & 21 & M & 256 & Middle-lower Pole & No & 56 & 86 & Subcostal & Nephrectomy & 1.2 & Stonefree \\
\hline 6 & 39 & $\mathrm{~F}$ & 280 & Pelvis & Yes & 60 & 89 & Subcostal & Nonfunctional & 1,7 & Stonefree \\
\hline 7 & 45 & $M$ & 900 & Pelvis & No & 60 & 354 & Subcostal & Nonfunctional & 2 & Stonefree \\
\hline 8 & 65 & $M$ & 500 & Pelvis & No & 60 & 138 & Subcostal & Nonfunctional & 0,7 & Stonefree \\
\hline 9 & 38 & M & 350 & Pelvis & No & 60 & 53 & Subcostal & Nonfunctional & 1,2 & $\begin{array}{c}\text { Residue } \\
\text { (more than } 4 \mathrm{~mm} \text { ) }\end{array}$ \\
\hline 11 & 33 & $M$ & 300 & Pelvis & Yes & 77 & 96 & Subcostal & Nephrectomy & 2,8 & $\begin{array}{c}\text { Residue } \\
\text { (less than } 4 \mathrm{~mm} \text { ) }\end{array}$ \\
\hline 12 & 55 & $M$ & 175 & Middle Pole & No & 30 & 139 & Intercostal & Nephrectomy & 1,9 & Stonefree \\
\hline 13 & 43 & $M$ & 250 & Pelvis & No & 65 & 140 & Intercostal & Nonfunctional & 1,6 & Stonefree \\
\hline 14 & 72 & $\mathrm{~F}$ & 1050 & Staghorn & No & 139 & 340 & Multiple access & Nephrectomy & 4.4 & $\begin{array}{c}\text { Residue } \\
\text { (more than } 4 \mathrm{~mm} \text { ) }\end{array}$ \\
\hline 15 & 41 & $M$ & 350 & Lower Pole & No & 25 & 45 & Subcostal & Nephrectomy & 1,8 & Stonefree \\
\hline 16 & 38 & M & 297 & Lower Pole & No & 40 & 150 & Subcostal & Nephrectomy & 1,2 & Stonefree \\
\hline 17 & 44 & $M$ & 100 & Lower Pole & Yes & 21 & 93 & Subcostal & Nephrectomy & 2 & Stonefree \\
\hline 18 & 59 & $M$ & 600 & Pelvis & No & 27 & 31 & Subcostal & Agenesis & 1,5 & Stonefree \\
\hline 19 & 14 & $\mathrm{~F}$ & 300 & Pelvis & No & 30 & 93 & Subcostal & Nephrectomy & 1,5 & Stonefree \\
\hline
\end{tabular}




\section{Discussion}

The main aim of PNL is to clear more calculi with the least morbidity. Although PNL is accepted as a minimal invasive treatment method, severe complications such as bleeding requiring transfusion, internal organ injuries, hydrothorax and sepsis can occur. Nephrectomy may be necessary due to uncontrollable bleeding. This event in a patient with solitary kidney involve that the patient will become anephric. A multi-center study of complications occurring after PNL was coordinated by the CROES (Clinical Research Office of the Endourological Society).

The Global PNL Study Group published it in 2011 reporting that general complication rate of PNL was 25\% (1175/5724); $80 \%$ of these were minor and 20\% major complications and the most common complications were fever and bleeding $(5,6)$.

Some studies showed that access to calyceal system can lead to a decrease in hemoglobin levels (2.1-3.3 g/dl.) (7). Bleeding after PNL can be prevented by clamping the nephrostomy tube. When bleeding cannot be stopped, selective arterial occlusion may be required (8, 9). Staghorn and large calculi, obesity, prolonged operation time and absence of hydronephrosis were reported as the risk factors causing excessive bleeding during PNL (10). In our study, average decrease in hemoglobin levels in postoperative period was $1.75 \mathrm{~g} / \mathrm{dl}$. In the treatment of staghorn calculi, more severe bleeding can occur due to need for multiple access (11). In fact the patient with staghorn calculus and multiple accesses was the patient with the most severe bleeding which caused $a<4.4 \mathrm{~g} / \mathrm{dl}$ decrease in the hemoglobin level.

It was stated that $28.7 \%$ of the patients with negative preoperative urine culture who had prophylactic antibiotic therapy developed fever after PNL and that urgent bacteriological evaluation was not necessary if hemodynamic stability was balanced in patients with negative preoperative urine culture who had fever higher than $38.5^{\circ} \mathrm{C}$ and started to receive prophylactic antibiotic therapy (12). In our series, 3 of 19 patients (15\%) developed fever after PNL, however none of them had sepsis. Pulmonary complications after PNL are usually seen in case of supracostal access. It was stated that pneumothorax and hydrothorax rate after PNL was about 6-12\% (6). Four patients needed supracostal access in our study, but we did not face with any pulmonary complication. Success rate after PNL ranges between 40\% and 90\% depending on number of stones, location, chemical structure and experience of the surgeon (12). Escape of the calculus or of its fragments to an unapproachable calyx and termination of operation due to bleeding or prolonged time can be the reasons for not providing a complete calculus clearance in PNL. Residual calculus fragments imply postoperative risks such as pain, urinary infection, calculus enlargement, obstruction and need for secondary surgery to patient. Therefore, it is quite important to obtain a stone-free status after PNL and non-contrast abdominal tomography was recommended for evaluation of stone-free situation (13). In our study, our success rate was estimated as $84 \%$ at first month postoperative control.

Modern treatment of upper urinary tract calculi of solitary kidneys includes mini-invasive techniques as ESWL,
PNL and retrograde intrarenal surgery (RIRS). In solitary kidney calculi, the results of ESWL treatment are promising and it was stated that ESWL was a safe and feasible method with low complications rates in the patients having only one kidney (14). Efficiency of ESWL was reported as 92\% for kidney calculi smaller than $10 \mathrm{~mm}$, 59$89 \%$ for $10-20 \mathrm{~mm}$ calculi and $39-70 \%$ for calculi larger than $20 \mathrm{~mm}$ (15). RIRS is a good option to remove kidney calculus in the patients having one kidney due to its high success and low morbidity rates. However, more than one procedure can be required for the patients having large urinary calculi $(16,17)$. Yet, there are limiting factors such as that RIRS is not available everywhere, operation duration is relatively longer, requires experience and is more suitable for $1.5-2 \mathrm{~cm}$ calculi.

Although PNL is today accepted as a safe and minimal invasive treatment method for treatment of urinary calculi, it is recommended that it should be always administered in high case-volume centers and by expert urologists in the patients with solitary kidney because of the risk of causing an anephric condition in case of severe complications (18). In the literature, success rates of PNL and its complications in the patients with a solitary kidney were reported in the range of acceptable levels $(19,20)$.

\section{Conclusions}

PNL can be effectively and safely administered for the treatment of solitary kidney. In the treatment of large urinary calculi in patients with a solitary kidney, PNL has some advantages such as short surgery duration, less complication, acceptable hemoglobin drawdown and high success rates. According to our study, PNL operation in patients with a solitary kidney is a good option for carefully and poisedly selected cases.

\section{REFERENCES}

1. Muslumanoglu AY, Binbay M, Yuruk E, et al. Updated epidemiologic study of urolithiasis in Turkey. I: Changing characteristics of urolithiasis. Urol Res. 2011; 39:309-14.

2. Akinci M, Esen T, Tellaloglu S. Urinary stone disease in Turkey: an updated epidemiological study. Eur Urol. 1991; 20:200-3.

3. Fernstrom I, Johansson B. Percutaneous pyelolithotomy. A new extraction technique. Scand J Urol Nephrol. 1976; 10:257-9.

4. Matlaga BR, Assimos DG. Changing indications of open stone surgery. Urology. 2002; 59:490-4.

5. Labate G, Modi P, Timoney A, et al. On Behalf Of The Croes Pcnl Study Group. The percutaneous nephrolithotomy global study: classification of complications. J Endourol. 2011; 25:1275-80.

6. Türk C, Knoll T, Petrik A, et al. Guidelines on Urolithiasis. European Association of Urology 2013.

7. Kessaris DN, Bellman GC, Pardalidis NP. Management of hemorrhage after percutaneous renal surgery. J Urol. 1995; 153:604-8.

8. Bedir S, Bozlar U, Tahmaz L, et al. Severe uncontrolled delayed bleeding after percutaneous nephrolithotomy. 24th World Congress of Endourology, August 17-20, Cleveland, Ohio, USA, 2006.

9. Keoghan SR, Cetti RJ, Rogers AE, Walmsley BH. Blood transfu- 
sion, embolisation and nephrectomy after percutaneous nephrolithotomy (PCNL). BJU Int. 2013; 111:628-32.

10. Nouralizadeh A, Ziaee SA, Hosseini Sharifi SH, et al. Delayed post percutaneous nephrolitotomy hemorrhage: Prevalance, predictive factors and management. Scand J Urol. 2013; 21.

11. Martin X, Tajra LC, Gelet A, et al. Complete staghorn stones: percutaneous approach using one or multiple percutaneous accesses. J Endourol. 1999; 13:367-8.

12. Cadeddu Ja, Chen R, Bishoff J, et al. Clinical significance of fever after percutaneous nephrolitotomy. Urology. 1998; 52:48.

13. Park J, Hong B, Park T, Park HK. Effectiveness of noncontrast CT. In evaluation of residual stones after percutaneous nephrolithotomy. J Endourol. 2007; 21:684-7.

14. Graff J, Diederichs W, Schulze H. Long term follow-up in 1003 extracorporeal shock wave lithotripsy patients. J Urol. 1988; 140:479-83.

15. Penn HA, DeMarco RT, Sherman AK, et al. Extracorporeal shock wave lithotripsy for renal calculi. J Urol. 2009; 182 (4 Suppl):1824-7.

16. Glustı G, Proietti S, Cindolo L, et al. Is retrograde intrarenal surgery a viable treatment option for renal stones in patients with solitary kidney?. World J Urol. 2014; 1-6.

17. Palmero JL, Castello A, Miralles J, et al. Results of retrograde intrarenal surgery in the treatment of renal stones greater than $2 \mathrm{~cm}$. Actas Urológicas Españolas. 2014; 38:257-262.

18. Mahboub DMR, Shakıb MH. Percutaneous nephrolithotomy in patients with solitary kidney. Urology journal. 2009; 5:24-27.

19. Akman T, Binbay M, Tekinarslan E, et al. Outcomes of percutaneous nephrolithotomy in patients with solitary kidneys: a singlecenter experience. Urology. 2011; 78:272-276.

20. Bucuras V, Gopalakrishnam G, Wolf JS, et al. The clinical research office of the endourological society percutaneous nephrolithotomy global study: nephrolithotomy in 189 patients with solitary kidneys. J Endourol. 2012; 26:336-341.

\section{Correspondence}

Tufan Süelözgen, $M D$

tsuelozgen@hotmail.com

Salih Budak,MD (Corresponding Author)

salihbudak1977@gmail.com

Orcun Celik, MD

orcuncelik82@hotmail.com

Okan Yalbuzdag, MD

Oguz Mertoglu, MD

Selcuk Isoglu, MD

selcukisoglu@hotmail.com

Mehmet Yoldas, MD

myoldas@hotmail.com

Yusuf Ozlem Ilbey, MD, Associate Prof.

ozlemyusufilbey@hotmail.com

Tepecik Training and Research Hospital, Urology Clinic, Izmir, Turkey 